\title{
Advancing Equity-Based School Leadership: The Importance of Family-School Relationships
}

\author{
Osly J. Flores \& Eric Kyere
}

\begin{abstract}
This narrative inquiry study presents the stories of five urban public school principals who continually enact and engage in praxis around school/family engagement as their social justice and equitable practices. The findings focus on how participants conceived and engaged in parent interaction: (1) the power of relationships, (2) resistance toward deficit thinking of parents and/or families, and (3) connecting their work with families to equity. An equity-based parent engagement model was developed on how the school leaders employ the power of relationships to engage parents, what participant interpreted their trusting relationship with parents reciprocated to them, and why they prioritize positive relationships with racially and ethnically diverse and economically disadvantage families. Overall, the findings extend emerging empirical research on the role of school leadership in effective parent engagement practice from an equity standpoint.
\end{abstract}

Keywords: school leadership, parent engagement, urban education, equity, social justice.

\section{Introduction}

Although state and federal policies and research suggest favorable outcomes are associated with positive parent engagement, yet such positive results have not loosen deficit perspective held by educators toward racially and ethnically diverse and economically disadvantaged children in K-12 urban education (Baquedano-Lopez, Alexander, \& Hernandez, 2013; Chavkin \& Williams, 1987; Diamond \& Gomez, 2004; Kim, 2009; Lightfoot, 2004; Watson \& Bogotch, 2015). In fact, moving to productive parent engagement from simply just rhetoric into action for racial and ethnic students as well as low-income families remains elusive (Chrispeels, 1991). Furthermore, despite the crucial role of school leadership to school family/parent engagement in supporting children in high need context to thrive academically (Barr \& Saltmarsh, 2014), the research related to the intersection between parent engagement 
and school leadership from equity standpoint remains underdeveloped (Auerbach, 2010; Green, 2018). Thus, research in the field of school leadership is limited in its ability to inform the field with evidence based practices and strategies by which educational leaders can advance educational justice and equity for historically marginalized students and those at-risk of being disenfranchised.

This interpretive qualitative inquiry aims to present the stories of five urban public educational school principals who continually enact and engage in praxis around school/family engagement that is bidirectional and centers on supporting students and parents and/or families to realize social justice in education. For this reason, this study is less concerned with parent involvement as it directly affects student outcomes (e.g., parent supplemental teaching or homework assistance) than with involvement as it affects school responsibility and the cultural climate schools create to deliver such responsibility. The perspectives and practices revealed in this article present timely and needed dialogue that offers best practice approach on how educators can examine, frame, and direct parent engagement in their schools.

This article opens with a description of the two-prong conceptual framework to parent engagement. Then, we present a closer examination of the literature relative to the narrative of schools and parent engagement, and the role school leadership in parent engagement. Third, we detail the use of narrative inquiry to capture the nuance of parent engagement practice of five urban school leaders. Next, this article provides the practices of social justice leadership for parent engagement by exploring the how, what, and the why school leaders see the value of building positive relationship with parents. Lastly, we provide a rich discussion with implication for theory and practice that underscore the significance of strong and trusting parent relationships for social justice and equity oriented school leaders in urban context. 


\section{Theoretical Framework}

The current investigation is informed by the synthesis of social justice leadership

(DeMatthews, 2018; Theoharis, 2007), and leadership for authentic partnership (Auerbach, 2010) frameworks. We recognize that social justice leadership entails complex roles and processes. To align with the purpose of this study, we focus on the specific features of parent engagement of social justice leadership. According to Theoharis (2007), social justice-oriented school leaders enact and sustain certain specific practices and approaches that lead to transformation in school culture including pedagogical practices, atmosphere, and school wide practices to benefit marginalized students and their families, by commitment and actions towards "addressing and eliminating marginalization in schools" (p. 223). Similarly, DeMatthews (2018) contends that justice leadership is being "about understanding context, problem-solving, engaging and empowering community to solve its own problems and taking action in ways that bring about distributive, cultural and associative justice" (p. 555).

Meanwhile, Auerbach (2010) theorizes that school-family partnership exists along a fourstage continuum—-leadership preventing partnerships, leadership for nominal partnerships, leadership for traditional partnership, and leadership for authentic partnership —moving from left to right, where leadership for authentic partnership is the desired goal. Auerbach (2010) defines authentic partnership as "respectful alliances among educators, families, and community groups that value relationship building, dialogue, and power sharing as part of socially just, democratic schools" (p. 729). Auerbach's conception of school-family partnership is consistent with our understanding that parent engagement should not only be about educators telling families about what they should do but establishing two-way communication whereby families and educators co-construct school culture for educating children.

\section{Literature Review}




\section{Parent engagement research}

Research has shown effective outcomes when schools purposely build positive relationship with parents and families (Ishimaru, 2013; Jeynes, 2018). For example, purposeful parent engagement has been known to positively influence student achievement (Fan \& Chen, 2001; Jeynes, 2018; Sheldon, 2003), decrease chronic absenteeism (Epstein \& Sheldon 2002), and improve the psychoeducational and health outcomes in students (CDC, 2012). A recent meta-analysis of the school-based component of parent/family-school involvement, partnership between parent and teachers had the largest effect size in student achievement (Jeynes, 2018).

Unfortunately, in the parent/family-school engagement literature, the dominant narrative describing parents and families both of students of color and of low-socioeconomic status (SES) reflects blame and/or deficit mindsets by public educators (Baquedano-Lopez et al., 2013; Comer, 2009; Diamond \& Gomez, 2004; Scheurich \& Skrla, 2003; Watson \& Bogotch, 2015). Prominent psychologist, James Comer (2009), details that when he began work to set up the progressive Yale Child Study Center in the late 1960's, the majority of the literature amplified deficit perspective about children and their families and the "substance and process of schooling was rarely, if ever questioned." (p. 10). The deficit narratives that characterize the public education in urban students, majority of whom are students of color, and live in under resource contexts continue to persist (Baquedano-Lopez et al., 2013). Research has shown most schools encounter challenges in supporting the involvement of parents of color and low-SES background, even when educators attempt to develop alternative engagement approach to counter deficit narratives of the community (Chrispeels, 1991; Lightfoot, 2004). Indeed, issues of power challenge community and family members from fully participating with school and rather 
schools seek parents to conform to the sanctioned roles and behaviors expected from the institutions of schooling (Jefferson, 2015).

A study by Blumer and Tatum (1999) in suburban context found that white teachers more often than not relied on inaccurate assumptions and misguided feelings of empathy toward black and Latino family racial and class circumstances. These in turn, influenced educators to have lower expectations and be unresponsive toward engaging parents of color. A plethora of work, from social justice and equity standpoint, shows that parent engagement approaches are Eurocentric and middle-class based, and are contingent on resources such as time, financial, cultural, and social capital that may be distinct for and limited to minority and low-income parents (Auerbach, 2009; Baquedano-Lopez et al., 2013; Lareau, 1987; Lareau \& Hovart, 1999; Lee \& Bowen, 2006). Yet, contrary to such misconceptions and judgments that less privileged and urban minority families do not care about their children's education, research suggests that these families do engage in their children's education in varied ways such as provision of emotional support, holding of expectations for grades and behaviors (Diamond \& Gomez, 2004). However, such forms of parent engagement may not be culturally consistent with the Eurocentric conception of parent engagement approaches. Consequently, the strengths diverse parents bring are more often than not ignored (Auerbach, 2009).

\section{School leadership and parent engagement}

School leadership is critical to the establishment and sustainability of effective parent/family school engagement that confers positive benefit on students' educational outcomes. The centrality of principals to effective family-school partnership is well acknowledged in equity and social justice literature on parent/family engagement (DeMatthews, Edwards, \& Rincones, 2016; Epstein et al., 2011; Author, 2018; Green, 2018; Green \& Gooden, 
2014; Ishimaru, 2013; Ishimaru \& Galloway, 2014; Theoharis, 2010). Collecting survey data from a sample of 407 schools in 24 school districts within 15 states, Epstein and peers (2011) identified principal support towards building positive partnership with parents as the strongest indicator of the schools' ability to support and advanced parent outreach. Green (2018), meanwhile, examined an urban black school leader who helped improve school-community relations by being a "social broker" who connected the school with community-based organizations (CBO). As a result, Green argues that a school leaders ability to broker relationships between CBOs in the community improves families and community members gain access to leverage self-improvement. A study by Author (2018) found that black female school leaders whose approach toward equity focused on building stronger relationship with families not only challenge deficit thinking of staff but also created opportunities for empowerment through relationship with churches and bringing GED programs to their school.

School leaders who value parent relationships engage in associational justice through shared governance and decision-making process with families and communities (DeMatthews, 2018). Although parent engagement is a significant dimension of the schooling experience that need to be present for students to maximize their potentials, more often schools and principals engage parents in one-way, rather than two-way, directional practice where schools are seen as holders of power and knowledge and parents as lacking interest or abilities (Chavkin \& Williams, 1987; Lopez, Scribner, \& Mahitivanichcha, 2001). DeMatthews and his colleagues (2016) provide an example of a two-way directional relationship from a case study of a Mexican American female school leader of an elementary school in Juarez, Mexico. According to DeMatthews and peers, the school leader did not see herself as the solver of the problems to support the achievement of students but rather she saw "families in collaboration with the school 
could collectively apply their skills and assets to empower each other and address commonly shared challenges" (p. 30).

Overall, substantive body of work exists suggesting that effective family/parent engagement is critical to schools ability to carry out the responsibility of educating children. Although best practice suggests parent engagement is a two-way directional relationship, the literature suggests that the one-way relationship that is often rooted in deficit perspective dominant parent engagement practices with less resourced as well as racially and ethnically diverse families. Emerging work suggests that social justice and equity oriented school leadership holds promise for leveraging on the benefits of family/parent to support diverse and high need students to thrive academically. However, research on the practices and approaches that justice and equity oriented leaders enact and engage in to initiate and sustain parent/family engagement in urban context is limited. More research that shed light on how these leaders shape parent/family engagement is needed.

\section{Methods}

This article focuses on the secondary analysis of data from a larger study of how eight principals direct their leadership toward equitable practices that enhance the learning for all students. For this study, we focus on five principals working in an urban environment who enact social justice practices to engage and empower parents and/or families. The first author used the qualitative methodology of narrative inquiry (Clandinin \& Connelly, 2000) to collect the lived experiences of principals. An "intensity sampling" (Patton, 2002) approach was used to identify the eight participants. According to Patton (2002), intensity sampling involves cases that are "information-rich" and require both prior information and considerable judgment. Thus, the first author used peers, community members, the university community, and his own background knowledge of the participants with leadership characteristics that underscore equity to select the 
school leaders for the larger study. The secondary analysis of data centers on those school leaders who view parent-school engagement as integral part of their social justice framework and who enact equity-based principles and strategies that embody their social justice orientation.

Three semi-structured interviews occurred over the course of the 2016-2017 academic school year. The range of each interview was between 30 minutes to 130 minutes. The interviews were tape-recorded and transcribed for the purpose of analysis. The data collected mapped the lived experience of the participants from their own experience as K-12 students to their current role as school principals. In addition, various documents were collected and analyzed: (a) external communication (i.e., newsletters, correspondence with parents and/or families), (b) internal documents (i.e., memos, professional development presentations, and meeting agendas), (c) personal documents (i.e., philosophy of education statements, poems, and completed survey response), (d) newspaper articles and videos, and (e) district accountability reports.

\section{Participants}

The five participants worked in urban schools located in the Northeast. Four were principals of elementary schools and one was the CEO of a K-8 charter school. They ranged in age from late 30 s to late 40 s and while all five had spent over a decade of their professional careers in education, the range in years in leadership roles was from 3 to 17 years. Four principals were black and one self-identified as white. Three participants were female and two were males (see Table 1). Although all the schools were identified as "community schools," the range in the number of students they served was from 260s to 900 s. All five principals served predominately students of color and of low-SES (see Table 2). We use pseudonyms for names and locations to protect the identity of our participants. 
[Insert Table 1 Here]

\section{Data analysis}

The first author conducted an extensive coding analysis during the data collection for the larger study. During the larger coding, the first author identified the five school leaders who identified parent engagement as an element of equitable practices. Again, the five participants used in this study reveal their work towards equity included parent engagement as embedded in their social justice framework. Consequently, for this study, we began the initial coding phase by using both Merriam's (2009) and Strauss and Corbin's (1998) qualitative data analysis based on a grounded theory approach.

The first phase of our secondary analysis began with the first and second author individually rereading the transcripts of the five chosen participants and used the analytical tool of open coding during the inductive approach, keeping track of key findings associated with parent engagement (i.e., relationships with parents, advocacy for parents, commitment to parents, communication with parents, and stories they shared about their work with parents). Next, we came together to discuss our findings and came to agreement about our initial analysis of the findings. Before returning to the data, we began researching the literature on parent engagement and social justice leadership.

In the second phase, we returned to the data using focused coding while using both a inductive and deductive coding process (Merriam, 2009) and grouping our open and focused codes using axial coding (Strauss \& Corbin, 1998) to identify connections between them. Following our second phase, we then proceeded to take a primarily deductive approach mapping our emergent themes and categories against the conceptual framework tenets to map out our three major findings. Lastly, for our final analysis, we generated a working model that helped us 
connect the reason the five participants connected relationship with parents as key driver of their equity focused initiative (see Figure 1).

Trustworthiness. The narrative study was designed with various strategies to help the first author capture a sense of saturation with the data-(1) three interviews, (2) transcriptions of the first and second interviews provided to participant to review, (3) a visual timeline of key ideas from the two interviews presented to participants as part of third interview. In addition, for the purpose of this secondary analysis, we included respondent validation (Merriam, 2009) by providing the participants with a draft of the manuscript to solicit their feedback on the themes that emerged from our analyses. Three of the five participants responded by affirming with no recommendation for any revisions.

[Insert Table 2 Here]

\section{Findings}

In the following section, we present findings focused on three main themes that characterized how these school leaders conceived and engaged in parent communication: (1) the power of relationships, (2) resistance toward deficit thinking of parents and/or families, and (3) connecting their work with families to equity. Next, we transition to the discussion and propose the emergent equity parent engagement model based on the data (see figure 1). Following the discussion, we provide germane implications for school leader practitioners and future research on school leadership and parent engagement.

\section{The Power of Relationships}

The five principals revealed the significant role of families in augmenting their efforts toward equity-based school culture and knowledge. Each participant believed that without a trusting relationship with parents, opportunity to leverage the strength and resources in families 
may be lost or underutilized. Parent school involvement thus provides the context for establishing a synergy between the school and the home for the benefit of the child. Trust, then, is a necessary ingredient for harnessing the particular expectations and obligations (Auerbach, 2010; Ishimaru, 2013; Lewis \& Forman, 2002; Strier \& Katz, 2016). For the participants in this study, the idea of human relationship was seen as central to genuine parent engagement. Dr. Thompson states, "I never shied away from difficult kids or difficult parents, [and] difficult communities ... human relationships were really important to me.” All participants shared a similar position as Dr. Thompson with respect to parents and families.

School leader Dr. Grant was beginning her fourth year at her urban elementary school. Dr. Grant serves a school with over $90 \%$ students of color and of whom $70 \%$ identified as lowsocioeconomic status (SES). Since her first year of taking on the principalship, Dr. Grant has worked tirelessly to build strong relationships with parents and families. In the following quote, Dr. Grant describes the importance of relationship with families this way,

Relationships teach you, relationships grow you, relationships change you, relationships make you better ... because of the relationships that we are able to build that, if I have a relationship with a parent, that parent trust me whole heartily, they [are] going to say [to their child], "You better go up to that school and listen to Dr. Grant."

For Dr. Grant, building relationships with parents and families is the starting point of the actualization of trust between school-and-home stakeholders. According to Dr. Grant, the power of relationship has been the fruition of trust as seen through parent support of the culture she has established in her school. 
Relationship building according to Dr. Grant has also helped establish a mutual respect that she uses to thrive in her urban elementary school. She shares that "my parents respect me, so I can thrive in this setting, and I can stay in it even when I'm tired, because I know what I do is valued." Similarly, in his three years as the principal of an urban elementary school, Dr. O'Neal has been open with parents in order to build strong relationships. Dr. O’Neal interprets his efforts to establish trusting relationships with parents, as "there is a level of respect when people see that you are advocating for the right stuff. Parents will support you . . . a lot of them would buy-in. So there is a level of respect." Thus, he believes the establishment of buy-in, leads to parents thinking, "I see where he is going, oh I see what he is attempting to do."

John Richardson has been leading a K-8 charter school located in an urban setting for over 15 years. He reflected about specific practices he picked up from school leaders while he was a teacher this way, "I also started taking things from, the people I knew were good." One of those lasting memories Richardson had was from the time when he was a teacher working in an alternative urban high school and witnessing the leadership of a school leader who would "break down walls." He recalls,

You know, you're at an alternative school and parents had been beat down, you know their kids were kicked out [of other schools] ... and in trouble. They [parents] would walk into a meeting and the first thing he [the principal of the alternative school] would do is make them laugh... They came with this wall and he would break down that wall.

Here, Richardson shares a story about a practice with parents performed by a school leader when he was a teacher that he found to be high-minded and effective. Indeed, Richardson started monthly family nights on the third Thursday of the month at his school the last 15 years because "those are to establish relationships with parents and kids." Now in his current role, Richardson 
tries to model the similar approach of breaking down walls and creating a welcoming environment (Theoharis, 2010).

\section{Resistance toward deficit thinking of parents and/or families}

Participant reveal three perspectives by which they resist and interrupt deficit orientation that undermine school leaders ability to fully leverage the benefits of authentic partnership with families to advance educational justice. School leaders in this study shed light on resistance against deficit thinking toward parents at both the external and personal level. The five school leaders frame their resistance from seeing families as a challenge by: (a) seeing challenges as opportunities, (b) confronting self, and (c) persisting when others want to quit. These three perspectives demonstrate the possibilities that can facilitate parent empowerment and building of relationships.

Seeing challenges as opportunities. Dr. Thompson provides the perspective of what seeing challenges as opportunities means to her. This perspective presents resistance toward external challenges. Dr. Thompson shared that "things that are considered challenges in some places, for me I see them as opportunities.” By seeing challenges as opportunities, she engages in exploration of alternative approaches that may better serve parents in ways sensitive to families relative to resources such as time and family arrangement. For example, Dr. Thompson describes an instance where she reframed the challenge the school had in engaging parents from the perspective of opportunity and made adjustment to respond. She shares the following story:

We were not getting a lot of parents in the evening for these parent school community council meetings. But I'm getting a lot of parents in the morning who are dropping their kids off. Well, shift it up ... You got parents who come into the cafeteria and they might even get a donut for themselves ... Change that challenge into an opportunity. So now I 
will have my mocha Mondays in the morning where I'm feeding the parents, feeding the children, and also talking about the issues of the school. So it's a win/win ... Feed them, give them some coffee and donuts and let's talk school. Let's talk kids and let me give you some space to share your truth with me. What do you need? How can I help you help yourself and help your family?

Dr. Thompson willingly removes inequities, by changing the school's structure for the benefits of parents and students instead of having parents adapt to the school's prescribed culture. Equityoriented leaders are not only culturally humble; they are creative and innovative in their approach to creating opportunities for parents to be actively involved (Green \& Gooden, 2014).

Persevering when others want to quit. Related to Richardson's previous strategy of creating monthly family nights to "break down walls," he went on to discuss how he has encountered some resistance to his family nights practice. This perspective also demonstrates the multitude of external conflict that results when school leaders engage in equitable parent engagement practices. Richardson shared that family nights are "from $6 \mathrm{pm}$ to $8 \mathrm{pm}$, teachers all have to be here ... [and] parents come in. You know, and teachers are telling me, 'ohhh parents . .. we've been doing them for so long."' Here, Richardson shares something of the semblance of resistance toward the practice of family nights by some staff members.

Nevertheless, Richardson maintains persistent and steadfast replies to those vacillating voices by responding that they will continue to hold family nights because "even if a parent comes in for two hours and gets nothing else out of it you're building that relationship-it's worth it." Richardson's position demonstrates how school leaders who value parents as assets in educating children, underscore relationship building as a mechanism for counteracting deficit mindsets. 
Confronting self to avoid crossing the border into deficit. There exist a small but emergent literature that humanizes the work of social justice leadership by calling attention to “justice dilemmas" (DeMatthews, 2016, 2018; Theoharis, 2007). In this article, we reveal the complex justice dilemma that even equity and socially just-minded school leaders must confront and interrupt in order to better serve marginalize families and communities. When asked what has been a challenge in her work towards equity, Dr. Grant took a long, deep sigh and said, "the first challenge I have everyday is I challenge my own white privilege. To be honest with you, 'cause I get upset, many times, with how parents show up and how they show up with their children." Although Dr. Grant is a black female, she acknowledges that in her position as principal within the institution of education has influenced her enculturation of elements of white privilege in her practice.

However, Dr. Grant uses both her spirituality and knowledge of social structure barriers to "have parents do some really funky stuff" to critically self-reflect in order to confront herself to avoid crossing the border into deficit thinking of families. According to Dr. Grant, she tries to check her deficit thinking at "the door and see how I still can be a support to that parent" and "begin [to] see how I can minister to the needs of my parents to get them on the road to whatever self-actualization that there is." It is important to see that even those school leaders who commit to improve the lives of all their students must challenge themselves through critical selfreflection. Similarly, Richardson shared his approach with parents is "I try to meet and greet every parent the same ... even if this parent cuss's you out the day before, or is mad and you can tell, you let that go." School leaders who work with parents with an equity mindset find techniques that build asset-based goal (Scheurich \& Skrla, 2003).

Parent-school involvement as an act of empowerment. 
The five principals interviewed regarded families as important stakeholders for achieving equity based education. By viewing parents as partners, these principals regard parents from a strength perspective, which in turn enables the leaders to treat parents with respect, love, and dignity. The leaders thus see parents beyond their social context and seek to support parents in areas that parents have need for support such as advocacy, education, and helping them cope with stress (Green, 2018). Therefore, the school leaders in this article rely on their asset-based relationship approach with their diverse families to advocate for parent empowerment. Empowerment entails making space available in the schools for parents to earn their GEDs, connecting them to the local community college, asking them to participate in building school policies and practices, and more importantly, providing them information about the educational system of the district.

Three foundational principles enable the school leaders to see parents beyond their social context: their own racialized positionalities, experience working with marginalized communities, and their own knowledge of, and motivation to interrogate and interrupt the dominant Eurocentric narrative that characterizes parent engagement. Dr. Grant shared that her empowerment efforts focus on providing supports to further parents' own education and their inclusiveness to building school policies. She detailed how her school brought in the "GED program to the school. I made sure that that happened here. We try to hook our parents up with, if you go through GED program how can we get you into [community college] or maybe possibly a university" and also engaged "our parents to help us shape our policies and practices and help us develop our discipline plan and really have their voice in how the school is made up." 
In a PowerPoint (PPT) presentation given to her faculty staff early in the new academic year, entitled, “Our Equity Journey,” Dr. Thompson highlighted major activities and accomplishments from the previous year including two prominent slides focused on parent engagement and community partnership. Consequently, we are able to get a closer examination of how this particular school leader strongly connects parent/community engagement to equity. A review of the two PPT slides on parent engagement showed seven activities that the school engaged in the previous school year: (1) "Mocha Mondays," (2) "Donuts with Dads," (3) Parent Resource Corner, (4) Take a Father to School Day, (5) Parent Teacher Conference Days, (6) Back to School Block Party, (7) Family Nights (Reading Math, Science). In addition, specific to community engagement, Dr. Thompson listed 11 community partnerships focused on themes such as cultural centers (arts), health and wellness/trauma centers, self-improvements (career fair), bullying prevention, academic (YMCA tutoring), sports (Squash), and gardening and planting clubs. Indeed, central to Dr. Thompson's pursuit of equity, a pursuit she describes as a journey, is building not only relationships but also empowering the parents and community (Green, 2018; Green \& Gooden, 2014; Watson \& Bogotch, 2015)

When asked about what he believes it will take to reach equity in education, Dr. O'Neal responded that it would occur when we are able to provide marginalized parents with the knowledge of their public educational rights,

I think it's gonna take - and this is another thing we try to do is we try to educate our parents, so that they know their rights when they leave here. We need, just like these White people, get out here, they get out here and they advocate for their kids. It's important for poor parents to do the same, and do it in large numbers. They need to be educated about the process, and they need to be taught this is how you advocate. 
Above, O'Neal shared the perspective that the more marginalized parents know what they should expect and demand out of the school, the more you can advise them to hold schools accountable. The efforts by each participant to empower families are also influenced by their knowledge that school systems more positively associate acceptable norms with Eurocentric, middle/upper-class positions.

Similar to socially justice-minded school leaders, O’Neal voices his interpretation about his students' parents this way, "I haven't come across a parent yet that does not want the best for their child." In an effort to help meet families need for them to be effective in their role as partners with the school, there is a pitfall to just teach parents how to behave. Yet, on the one hand, all the participants who worked in the large urban school district also recognize that some parents may lack the knowledge of "how to navigate the system;" such as school choice, magnet school registration, and requesting a bus stop. On the other hand, leaders who view parent engagement as an equity and justice issue, recognize not only the challenges the families face but also recognize resilience and engage them from strength perspective in an effort to remove the barriers to parents' full involvement with the school for better outcomes of their children. Parent engagement thus, suggests a process of empowering parents for building and utilizing advocacy skills.

\section{Discussion}

In the current study, we seek to contribute to expanding our knowledge of social justice and equity oriented school principals beliefs around school-parent/family engagement, and the specific practices and behaviors they enact to reflect such orientations. We did this through an intensive qualitative exploration of five principals' - deemed to be socially just and equity minded — narratives of their educational experiences. The stories by school leaders of their educational experiences can reveal rich contextual information. In fact, personal narratives can 
reveal how research participants in ethically complex settings—-like schools—are social beings who are actively engaged in negotiating school structures and social forces that impact the dreams and possibilities of all students (DeMatthews, 2018; Theoharis, 2007).

The themes revealed through these stories highlight the critical role that relationship with parents by school leaders can contribute to effective parent-school engagement in ways that are culturally and contextually responsive, and empower parents to help their children achieve better educational outcomes. The findings suggest that the power of relationships, resistance toward deficit thinking of parents and/or families, and connecting their work with families to equity influence our participants' school leadership relative to parents/families in urban communities. Consequently, we developed a model to further elaborate on our interpretation of why these five school leaders worked so hard to build positive relationship with parents (see figure 1). [Insert Figure 1 Here]

The model contributes to the parent engagement literature by highlighting equity-minded school leaders' mechanism and underlying value of parent/family engagement. First, the how school leaders go about family/parent' engagement from social justice and equity standpoint is; building trusting relationship, resistance toward deficits-thinking, and equitable practices; followed by the what school leaders see as the outcomes of positive relationships with parents: recognition from parents of their commitment to students, support of school leaders goals, and trust of their leadership decision-making; and finally the why school leaders seek such relationships is because it provides greater opportunities for student success.

In the how, school leaders first work to build relationship with parents to establish the context that facilitate the actualization of educational mandate. Through this relationship, trust between the leaders and the families are established. As revealed through the findings, families 
trust the leaders because they recognize that the schools' policies and practices are in their interest relative to their children. In turn, the school leaders are able to recognize the asset that is inherent in the families despite the historical barriers diverse and low-SES communities face in accessing education. Such knowledge fosters empathy and compassion enabling these school leaders to strengthen trusting relationship with parents/families (Lewis \& Forman, 2002; Strier \& Katz, 2016; Theoharis, 2010).

Within the context of positive relationships with parents the leaders ability to resistboth internal and external voices - from seeing families as a challenge. The findings in this study are consistent with findings noted in the parent engagement literature that calls for educators to critically self-reflect in order to refrain from deficit thinking of families (DeMatthews, 2016; Scheurich \& Skrla, 2003; Lightfoot, 2004). Additionally, the findings here also extend prior work by providing examples of specific application of ideas, beliefs, and processes germane to maximize the benefits of parent/family engagement. Moreover, the findings further underscore the significance that socially justice and equity-focused parent engagement practices require sustained review of introspective leadership dilemmas (DeMatthews, 2016, 2018; Theoharis, 2007). Thus, equity-minded school leaders recognize that they work in institutions that can be very oppressive and therefore, develop critical self-reflection to ensure that they do not become an arm of oppressive apparatus.

The third practices that supported positive relationships with parents was the participants commitment to promote associational justice whereby they engage in advocacy and empowerment or capacity building to ensure traditionally marginalized communities and families' have a voice within the often exclusionary educational institutions (Author, 2018; Auerbach, 2010; Baquedano-Lopez et al., 2013; Lareau \& Hovart, 1999). By so doing, justice 
minded leaders tend to view parent/family-school engagement as an act of empowerment, whereby they attend to the power dynamics by educating adults as a way of creating opportunities for families in need to be well positioned so that they can be actively engaged with the school for the education of children (Ishimaru, 2013). The study further reveals how school leaders who interpret parents from a strength-based perspective seek to empower parents to achieve self-improvement and the knowledge of navigating the institution of schooling (Lopez et al., 2001). Overall, these three themes supported the how school leaders work to build trusting relationships with their students' parents.

The current study sheds lights on school leadership and parent engagement by providing an awareness of what school leaders recognize as the outcomes of positive relationships with parents - recognition of their commitment, support of their leadership goals, and faith in their decision-making. Few studies have captured the essence of how school leaders interpret the outcomes of positive relationship with parents. As the equity oriented parent engagement model demonstrates, school leaders perceive significant returns from bridging parents and school. In fact, Dr. Thompson shared that she has heard "parents engaging in conversations where they're talking about having an appreciation for the culture of the school" and principal Stanfield argues that "a larger cohort of parents now" who "really understand and kind of see who I am." Dr. O'Neil interpret "if that relationship is there with them [parents], they'll go to the moon and back for you." Moreover, because of the parent support, participants were able to sense an awareness of strength and vitality required against sustained physical and mental challenges.

As the equity parent engagement model displays, who participants built positive relationship with parents in mind was their belief that through relationship they can actualize the educational improvement of their students. Indeed, the current findings support the important 
role that trustful relationship can play in family/parent-school partnership, but more so, the central role of the school leadership in establishing and maintaining school-family/parent engagement as an equity-based approach to educating children from high need or under resourced communities (Chrispeels, 1991). On the whole, from frameworks of social justice leadership (Theoharis, 2007; DeMatthews, 2018), and leadership for authentic partnership (Auerbach, 2010), the participants in the current study view parent engagement as a process to identify and leverage on the distinct support/resources of parents to help students. They believe that their parent engagement practices are acts of equitable practices. Furthermore, relationship is the central mechanism by which the beliefs, practices, and behaviors of these leaders are translated into action.

\section{Implication}

The findings have several implications for educators who serve diverse children as well as those from high need urban context. First, for principals who view education as a tool to advance educational justice, parent-school partnership that is rooted in positive relationship may be one key mechanism. Although relationship is the end goal, it is important that school leaders prioritize intentional effort to cultivate and maintain trusting relationships with families/parents because it critical for the kind of synergy needed between families/parents for the implementation of policies and practices that advance educational justice and equity.

In their efforts to cultivate and sustain trustful relationship with families, there is the need for school leaders to engage in critical reflection of their positions as agents of institutions designed to elevate and perpetuate white privilege_- "a social construction that embraces white culture, ideology, racialization, expressions and experiences, epistemology, emotions, and behaviors that get normalized because of white supremacy" (Matias, 2013, p.69). As 
demonstrated in our findings, such critical reflection is necessary to interrogate and interrupt the structural influence of educators in their engagement with racially and ethnically diverse as well as lower SES families.

In addition, it is essential that educators, principals in particular, explore families/parents resources and needs through the relationship, and facilitate the development of programs, activities, and services that activate the resources families bring and to help meet areas of need so that they can be positioned to be true partners/collaborators to deliver educational mandates to children. Leadership may facilitate advocacy and empowerment programs such as educating parents/families of how to hold schools accountable, connecting families to information and resources in the community (e.g. GED programs, connection to community colleges, trauma and mental health services).

Moreover, the current findings imply the need to expose school leaders to training that help them understand the social justice and equity needs of families/parents and communities that they would be serving, and equip them with the knowledge and skills to be creative and innovative in facilitating parent/family engagement. One way this can be accomplished is through University-urban community partnership, where principals in training as well as preservice teachers can observe and learn from social justice and equity minded leaders in their pursuit of parent/family engagement agenda.

Although our participants seem transformative, social justice focused, and engages in democratic participation, we also acknowledge that they are functioning within a context that is largely influenced by social and structural forces that are outside of the school's domain. This suggests that these leaders potentially face social justice dilemmas, which can influence how social justice issues are prioritized and responded to, and sometimes compromising social justice 
goal (DeMatthews, 2018). Thus, the findings here by no means suggest that social justice and equity based practices of school leadership alone can address the complex structural forces that influence parents/families' capacities to be actively engaged with schools toward the education of children. Nevertheless, school leaders are well positioned to begin shifting their schools towards becoming more welcoming and empowering to racially and ethnically diverse and economically disadvantaged children in K-12 urban education.

Equity oriented leaders understanding of the unique contributions of the family and schools in children development position them to view school-family involvement as one of partnership in a bidirectional way. Parents, those with history of marginalization in particular, are viewed from a strength perspective, as resources critical to transformative school climate. Trustful relationship with families and communities serves as the key mechanisms by which these school leaders enact their practices in ways that attend to the principles of democratic participation, social justice needs of the families/communities they serve, and culturally responsive engagement with families (Auerbach, 2010; DeMatthew, 2018, Theoharis, 2007). Therefore, the importance of building trusting relationship with parents works to help school leaders achieve a synergistic link between educators and families to serve as a catalyst for better educational outcomes for children. Here, school leaders who hold positive relationships as valuable embody the characteristics of school leaders who value authentic partnership with parents and communities. 


\section{References:}

Auerbach, S. (2009). Walking the walk: Portraits in leadership for family engagement in urban schools. The School Community Journal, 19(1), 9-32.

Auerbach, S. (2010). Beyond coffee with the principal: Toward leadership for authentic schoolfamily partnerships. Journal of School leadership, 20(6), 728-757.

Baquedano-Lopez, P., Alexander, R. A., \& Hernandez, S. J. (2013). Equity issues in parental and community involvement in schools: What teachers need to know. Review of Research in Education, 37(1), 149-182.

Barr, J., \& Saltmarsh, S. (2014). "It all comes down to the leadership": The role of the school principal in fostering parent-school engagement. Educational Management Administration \& Leadership, 42(4), 491-505.

Blumer, I., \& Tatum, B. D. (1999). Creating a community of allies: How one school system attempted to create an anti-racist environment. International Journal of Leadership in Education, 2(3), 255-267.

CDC. (2012). Promoting parent engagement: Improving student health and academic achievement.

Chavkin, N. F., \& Williams, D. L. (1987). Enhancing parent involvement: Guidelines for access to an important resource for school administrators. Education and Urban Society, 19(2), 164-184.

Chrispeels, J. H. (1991). District leadership in parent involvement: Policies and actions in San Diego. The Phi Delta Kappan, 72(5), 367-371.

Clandinin, D, \& Connelly, M. (2000). Narrative inquiry. San Francisco, CA: Jossey-Bass. Comer, J. (2009). What I learned in school: Reflection on race, child development, and school 
reform. San Francisco, CA: Jossey-Bass.

DeMatthews, D. (2018). Social justice dilemmas: Evidence on the successes and shortcomings of three principals trying to make a difference. International Journal of Leadership in Education, 21(5), 545-559.

DeMatthews, D. E., Edwards, D. B., \& Rincones, R. (2016). Social justice leadership and family engagement: A successful case from Ciudad Juarez, Mexico. Educational Administration Quarterly, 52(5), 1-39.

Diamond, J. B., \& Gomez, K. (2004). African American parents' educational orientations: The importance of social class and parents' perceptions of schools. Education and Urban Society, 36(4), 383-427.

Epstein, J. L., Galindo, C. L., \& Sheldon, S. B. (2011). Levels of leadership: Effects of district and school leaders on the quality of school programs of family and community involvement. Educational Administration Quarterly, 47(3), 462-495.

Epstein, J., \& Sheldon, S. B. (2002). Present and accounted for: Improving student attendance through family and community involvement The Journal of Educational Research, 95(5), 308-318.

Fan, X., \& Chen, M. (2001). Parental involvement and students' academic achievement: A metaanalysis. Educational Psychology Review, 13(1), 1-22.

Author (2018).

Green, T. L. (2018). School as community, community as school: Examining principal leadership for urban school reform and community development. Education and Urban Society, 50(2), 111-135.

Ishimaru, A. (2013). From heroes to organizers: Principals and education organizing in urban 
school reform. Educational Administration Quarterly, 49(1), 3-51.

Ishimaru, A. M., \& Galloway, M. K. (2014). Beyond individual effectiveness: Conceptualizing organizational leadership for equity. Leadership and Policy in Schools, 13(1), 93-146.

Jefferson, A. (2015). Examining barriers to equity: School policies and practices prohibiting interaction of families and schools. The Urban Review, 47(1), 67-83.

Kim, Y. (2009). Minority parental involvement and school barriers: Moving the focus away from deficiencies of parents. Educational Research Review, 4(2), 80-102.

Lareau, A., \& Horvat, E. M. (1999). Moments of social inclusion and exclusion, race, class, and cultural capital in family-school relationships. Sociology of Education, 72(1), 37-53.

Lee, J. S., \& Bowen, N. K. (2006). Parent involvement, cultural capital, and the achievement gap among elementary school children. American Educational Research Journal, 43(2), 193218.

Lewis, A. E., \& Forman, T. A. (2002). Contestation or collaboration? A comparative study of home-school relations. Anthropology \& Education Quarterly, 33(1), 1-30.

Lightfoot, D. (2004). "Some parents just don't care" decoding the meanings of parental involvement in urban schools. Urban Education, 39(1), 91-107.

Lopez, G. R., Scribner, J. D., \& Mahitivanichcha, K. (2001). Redefining parental involvement: Lessons from high-performing migrant-impacted schools. American Educational Research Journal, 38(2), 253-288.

Matias, C. E. (2013). Check yo'self before you wreck yo'self and our kids: Counterstories from culturally responsive white teachers?...To culturally responsive white teachers!. Interdisciplinary Journal of Teaching and Learning, 3(2), 68-81.

Merriam, S. B. (2009). Qualitative research: A guide to design and implementation. San 
Francisco, CA: Jossey-Bass.

Patton, M.Q. (2002). Qualitative research and evaluation methods ( $3^{\text {rd }}$ ed.). Thousand Oaks, CA: Sage Publications.

Scheurich, J. J. (1998). Highly successful and loving, public elementary schools populated mainly by low-ses children of color core beliefs and cultural characteristics Urban Education, 33(4), 451-491.

Scheurich, J.J. \& Skrla, L. (2003). Leadership for equity and excellence. Thousand Oaks, CA: Corwin Press.

Sheldon, S. (2003). Linking school-family-community partnerships in urban elementary schools to student achievement on state tests. The Urban Review, 35(2), 149-165.

Strauss, A.L. \& Corbin, J.M. (1998). Basics of qualitative research: Techniques and procedures for developing grounded theory. Thousand Oaks, CA: Sage Publications.

Strier, M., \& Katz, H. (2016). Trust and parents' involvement in schools of choice. Educational Management Administration \& Leadership, 44(3), 363-379.

Theoharis, G. (2007). Social justice educational leaders and resistance: Toward a theory of social justice leadership. Educational Administration Quarterly, 43(2), 221-258.

Theoharis, G. (2010). Disrupting injustice: Principals narrate the strategies they use to improve their schools and advance social justice. Teachers College Record, 112(1), 331373.

Watson, T. N., \& Bogotch, I. (2015). Reframing parent involvement: What should urban school leaders do differently? Leadership and Policy in Schools, 14(3), 257-278. 
Table 1. Background demographic of participants and experience in education information.

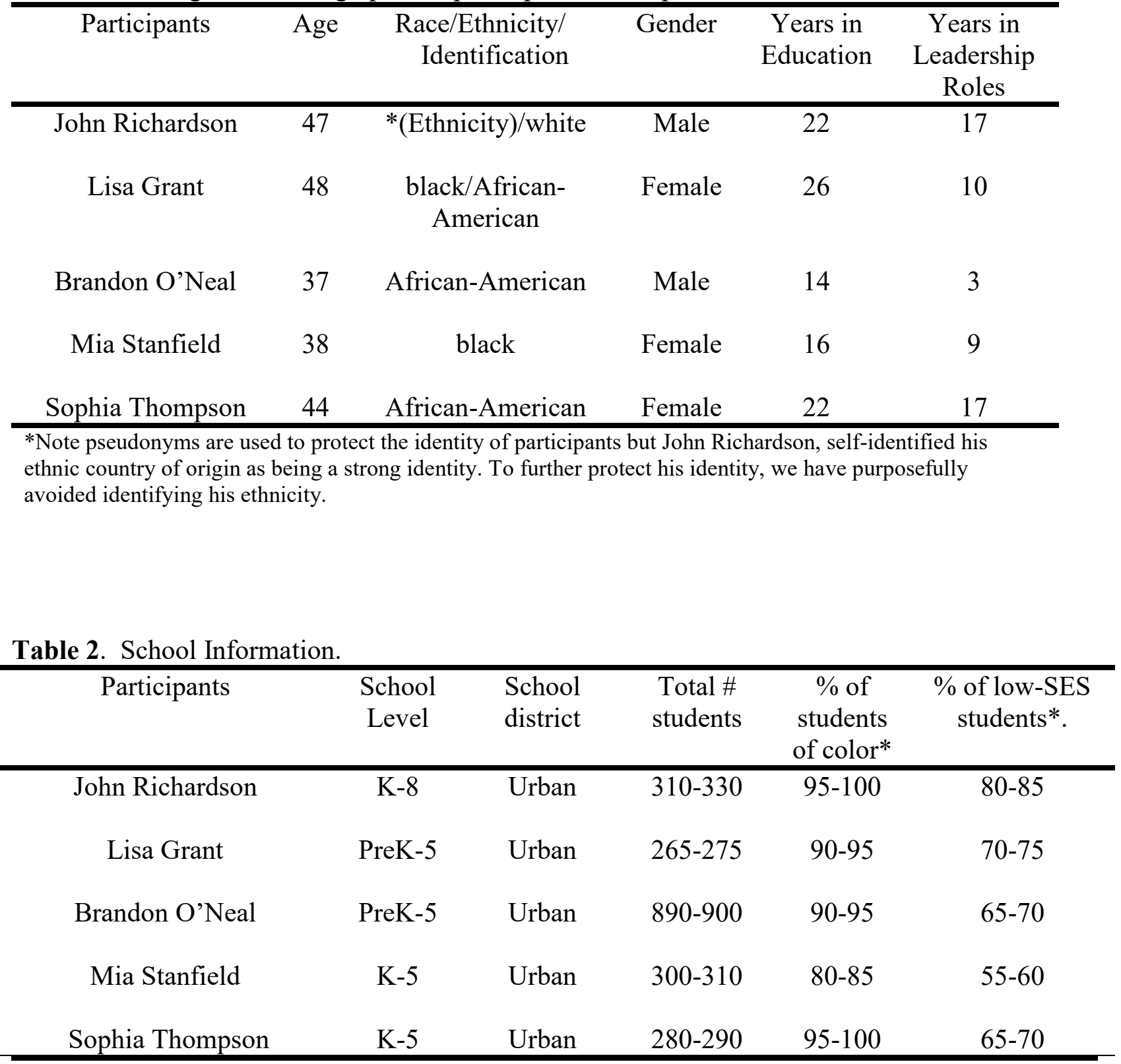

Note: Pseudonyms are used and percentage of students of color and of students on free and reduce lunch have been given in ranges to protect the identities of participants.

* The state's 2016 school performance profile data is used. 
Figure 1: Equity Parent Engagement Model

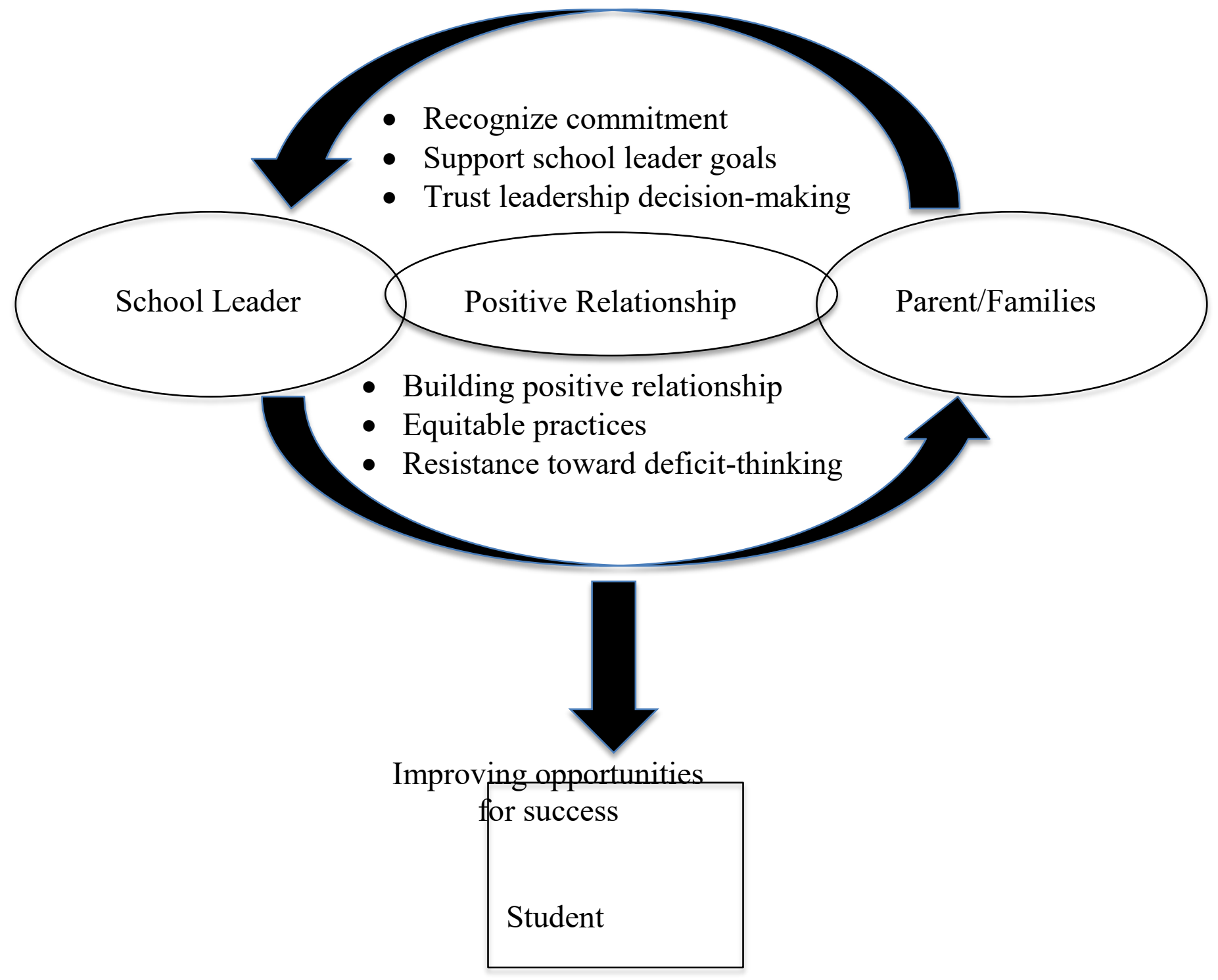

